\title{
Association between Airflow Obstruction and the Metabolic Syndrome or Its Components in Japanese Men
}

\author{
Yayoi Funakoshi ${ }^{1}$, Hisamitsu Omori ${ }^{1}$, Shuichi Mihara ${ }^{2}$, Tohru Marubayashi ${ }^{2}$ and \\ Takahiko Katoh $^{1}$
}

\begin{abstract}
Background The aim of this cross-sectional study was to investigate the association between airflow obstruction and the metabolic syndrome (MS) or its components in Japanese men.

Methods The study included 7,189 male subjects, aged 45-88 years, who underwent spirometric lung function tests at a medical check-up. The spirometric criteria for diagnosis of airflow obstruction were forced expiratory volume in 1 second $\left(\mathrm{FEV}_{1}\right)$ /forced vital capacity $(\mathrm{FVC})<70 \%$. The severity of airflow obstruction was defined according to the Global Initiative for Chronic Obstructive Lung Disease (GOLD) guideline.

Results The prevalence of airflow obstruction was 9.0\% and the frequency of MS was 25.6\%. In logistic regression models adjusting for age, body mass index, smoking, and alcohol, the risk of MS was higher in subjects with airflow obstruction of GOLD stage II-IV compared to those with normal lung function [odds radio (OR), 1.33; 95\% confidence interval (95\% CI), 1.01-1.76)]. Of the MS components, waist circumference (OR, 1.76; 95\% CI, 1.24-2.50) and blood pressure (OR, 1.37; 95\% CI, 1.08-1.74) were associated with airflow obstruction of GOLD stage II-IV, after controlling for potential confounders.

Conclusion Airflow obstruction of GOLD stage II-IV might be associated with MS, waist circumference and blood pressure components in Japanese men.
\end{abstract}

Key words: airflow obstruction, lung function tests, metabolic syndrome, spirometry

(Inter Med 49: 2093-2099, 2010)

(DOI: 10.2169/internalmedicine.49.3882)

\section{Introduction}

Chronic obstructive pulmonary disease (COPD) is a chronic inflammatory disease of the airways that is characterized by chronic airflow obstruction and an abnormal inflammatory response of the pulmonary tissue (1). COPD is a major cause of morbidity and mortality throughout the world (1). In addition, COPD is predicted to become the third leading cause of deaths worldwide by 2020 (2). In Japan, the NIPPON COPD epidemiological (NICE) study in 2004 showed that at least $8.6 \%$ of the general population suffered from COPD (3). The Global Initiative for Chronic Obstructive Lung Disease (GOLD) Guidelines recommended effective COPD management and prevention strategies (1). Therefore, it is important to attempt to identify illnesses that are frequently linked with COPD and assess their impact on the way the disease progresses.

Individuals with COPD show evidence of systemic inflammation including coronary artery disease, diabetes, hypertension, osteoporosis, and muscle weakness (1, 4-9). Thus, it is thought that COPD is not only a disease of the lungs but is also a systemic inflammatory disorder (10). Fabbri and Rabe suggested adding the term "chronic systemic inflammatory syndrome", which includes such entities as COPD, chronic heart failure and metabolic syndrome (MS), to the diagnosis of COPD (6). MS represents a cluster of risk factors (abdominal obesity, atherogenic dyslipidemia, elevated blood pressure, and elevated fasting glucose) that predispose affected patients to systemic inflammation (11). Recently, particular attention has been focused on the finding that MS is common in patients with COPD (12). Sys-

${ }^{1}$ Department of Public Health, Faculty of Life Sciences, Kumamoto University, Kumamoto and ${ }^{2}$ Japanese Red Cross Kumamoto Health Care Center, Kumamoto

Received for publication April 27, 2010; Accepted for publication July 6, 2010

Correspondence to Dr. Hisamitsu Omori, omorih@gpo.kumamoto-u.ac.jp 
temic inflammation may be related to the pathogenesis of both COPD and MS (10).

A study suggested that airflow obstruction was associated with MS in Chinese (13), however no previous studies have exclusively targeted Japanese. In Japan, COPD is observed more often and is more serious in men than women $(3,14)$. The aim of this cross-sectional study was to investigate the association between airflow obstruction and MS or its components in Japanese men.

\section{Methods}

\section{Subjects}

The study included 7,189 male subjects, aged 45-88 years, who underwent a comprehensive health screening, which included a physical examination, spirometry, chest Xray and blood tests held between April 2008 and March 2009 at the Japanese Red Cross Kumamoto Health Care Center, Kumamoto, Japan. Data on medical history and lifestyle information were collected by means of interview questionnaires conducted by a public health nurse. All subjects were evaluated by a physician. Subjects with physician-diagnosed asthma or a history of asthma or asthma-like symptoms were excluded from a diagnosis of COPD based on self-reported diagnosis and symptoms as described in the NICE study (3). Subjects were also excluded if they had physician-diagnosed bronchiectasis, tuberculosis or malignancy. Thus, people with a physiciandiagnosed asthma or individuals who had other pulmonary diseases were excluded. Subjects with infectious disease, or other diseases associated with systemic inflammation, such as rheumatoid arthritis, connective tissue disorders or inflammatory bowel disease, were also excluded, as these diseases may influence CRP levels. All subjects were clinically stable (no exacerbation during the previous 2 months) at the time of evaluation. Subjects with a history of workplace dust exposure were also excluded. Our research protocol was approved by the Human Ethics Committee of $\mathrm{Ku}-$ mamoto University and Japanese Red Cross Kumamoto Health Care Center. All subjects gave informed consent prior to receiving the spirometric lung function tests.

\section{Measurements}

After an overnight fast, blood samples were obtained to measure serum levels of routine medical check-up markers: triglycerides, high-density lipoprotein cholesterol (HDL-C), fasting glucose, C-reactive protein (CRP) and white blood cell count. CRP levels were measured using a highsensitivity latex assay. Percentage body fat was measured by bioelectrical impedance analysis using BF-220 (TANITA, Tokyo, Japan). Waist circumference was measured at the level of the umbilicus. An average blood pressure was calculated from two measurements with the subjects in a sitting position after 5 min of rest. Body mass index (BMI) was calculated as the weight in kilograms divided by the height in meters squared. A detailed smoking history was obtained and used to define individuals as "never smokers" (those who denied past and current smoking), "former smokers" (those who reported smoking prior to the examination and denied current smoking at examination), or "current smokers" (those who reported smoking at least 1 cigarette a day). Pack-years (packs of cigarettes per day multiplied by smoking years) was used as the smoking index. Alcohol intake was classified into five categories: "non-drinkers", "1-2 days per week", "3-4 days per week", "5-6 days per week" and "everyday drinkers".

\section{Metabolic syndrome}

MS was defined in accordance with the revised National Cholesterol Education Program (NCEP)-Adult Treatment Panel III (ATP III) criteria (15) as three or more of the following five components: I) waist circumference, in which the cutoff point was modified for Japanese individuals to 90 $\mathrm{cm}$; II) triglycerides, $\geq 150 \mathrm{mg} / \mathrm{dL}$; III) HDL-C, $<40 \mathrm{mg} / \mathrm{dL}$; IV) blood pressure, systolic blood pressure (SBP) $\geq 130$ $\mathrm{mmHg}$ and/or diastolic blood pressure (DBP) $\geq 85 \mathrm{mmHg}$; V) fasting glucose, $\quad \geq 100 \mathrm{mg} / \mathrm{dL}$. Subjects receiving antihypertensive agents or hypoglycemic medication were considered to have the respective components.

\section{Lung function tests}

Lung function tests were performed using an electric spirometer (DISCOM-21 FX: CHEST MI, Tokyo, Japan) connected to a computer for analysis of data, as described previously (16). Maneuvers were performed according to GOLD recommendation (1) under the supervision of a certified pulmonary technologist. No reversibility test was performed. The spirometric criteria for diagnosis of airflow obstruction were forced expiratory volume in 1 second $\left(\mathrm{FEV}_{1}\right) /$ forced vital capacity (FVC) $<70 \%$. $\mathrm{FEV}_{1} \%$ predicted is expressed as percentages of predicted values using the predictive equations published by the Japanese Society of Chest Disease (17). Normal lung function was defined as $\mathrm{FEV}_{1}$ / $\mathrm{FVC} \geq 70 \%$ and $\mathrm{FEV}_{1} \geq 80 \%$ predicted.

\section{Classification of severity}

Severity of airflow obstruction was defined analogously to the GOLD guidelines (1) as follows: GOLD stage I: $\mathrm{FEV}_{1} /$ FVC $<70 \%$ and $\mathrm{FEV}_{1} \geq 80 \%$ predicted; GOLD stage II-IV: $\mathrm{FEV}_{1} / \mathrm{FVC}<70 \%$ and $\mathrm{FEV}_{1}<80 \%$ predicted. The subjects were divided into three groups: a control group (normal lung function), GOLD stage I, and GOLD stage II-IV. Subjects with GOLD stage II and higher have consistently been associated with increased mortality in epidemiological studies using pre-bronchodilation spirometry (18-21). Therefore we combined GOLD stages II, III and IV, and compared this group to subjects with normal lung function or GOLD stage I.

\section{Statistical analysis}

Results are presented as the mean \pm standard deviation 
Table 1. Characteristics of the Subjects by Lung Function Status

\begin{tabular}{|c|c|c|c|c|}
\hline & \multirow{2}{*}{$\begin{array}{l}\text { Normal lung } \\
\text { function } \\
(n=6,544)\end{array}$} & \multicolumn{2}{|c|}{ Airflow obstruction } & \multirow[b]{2}{*}{$\mathrm{p}$} \\
\hline & & $\begin{array}{l}\text { GOLD stage I } \\
\qquad(\mathrm{n}=297)\end{array}$ & $\begin{array}{l}\text { GOLD stage II } \sim \mathrm{IV} \\
\qquad(\mathrm{n}=348)\end{array}$ & \\
\hline Age (yr) & $55.9 \pm 7.9$ & $62.3 \pm 9.3 *$ & $61.3 \pm 9.2 *$ & $<0.001$ \\
\hline Weight (kg) & $67.2 \pm 9.5$ & $64.0 \pm 8.5^{*}$ & $64.5 \pm 9.7^{*}$ & $<0.001$ \\
\hline Body fat (\%) & $22.0 \pm 4.7$ & $19.9 \pm 4.3^{*}$ & $21.6 \pm 4.9^{\#}$ & $<0.001$ \\
\hline BMI $\left(\mathrm{kg} / \mathrm{m}^{2}\right)$ & $23.7 \pm 2.8$ & $22.7 \pm 2.4^{*}$ & $23.1 \pm 2.9^{*}$ & $<0.001$ \\
\hline $\mathrm{FEV}_{1} \%$ predicted & $95.8 \pm 9.8$ & $89.0 \pm 7.8 *$ & $66.6 \pm 11.5^{* \#}$ & $<0.001$ \\
\hline $\mathrm{FEV}_{1} / \mathrm{FVC}(\%)$ & $79.5 \pm 4.7$ & $66.1 \pm 3.0 *$ & $62.3 \pm 7.0^{* \#}$ & $<0.001$ \\
\hline Waist circumference $(\mathrm{cm})$ & $85.6 \pm 7.6$ & $83.9 \pm 6.4^{*}$ & $85.7 \pm 7.9^{\#}$ & $<0.001$ \\
\hline Triglycerides (mg/dL) & $141.2 \pm 108.5$ & $127.8 \pm 86.8$ & $131.1 \pm 83.5$ & $<0.05$ \\
\hline HDL-cholesterol (mg/dL) & $61.2 \pm 15.9$ & $63.1 \pm 16.0$ & $60.8 \pm 16.7$ & 0.12 \\
\hline Systolic blood pressure (mmHg) & $123.0 \pm 16.3$ & $123.7 \pm 18.3$ & $126.2 \pm 17.6^{*}$ & $<0.05$ \\
\hline Diastolic blood pressure $(\mathrm{mmHg})$ & $77.1 \pm 11.2$ & $74.7 \pm 10.9^{*}$ & $75.7 \pm 11.7^{*}$ & $<0.001$ \\
\hline Fasting glucose $(\mathrm{mg} / \mathrm{dL})$ & $106.0 \pm 22.1$ & $103.6 \pm 18.1$ & $106.4 \pm 21.4$ & 0.18 \\
\hline \multicolumn{5}{|l|}{ Medication } \\
\hline Treatment for dyslipidaemia \% & 8.5 & 8.8 & $12.4^{*}$ & $<0.05$ \\
\hline Treatment for hypertension $\%$ & 20.7 & 18.5 & $28.7 * \#$ & $<0.05$ \\
\hline Treatment for diabetes $\%$ & 5.4 & 4.0 & 8.0 & 0.06 \\
\hline Metabolic syndrome $\%$ & 25.8 & $16.8^{*}$ & $28.7^{\#}$ & $<0.001$ \\
\hline Elevated waist circumference $\%$ & 28.8 & $17.8^{*}$ & $29.9^{\#}$ & $<0.001$ \\
\hline Elevated triglycerides $\%$ & 36.4 & 30.6 & 34.2 & 0.10 \\
\hline Reduced HDL-cholesterol \% & 4.4 & 3.7 & 5.7 & 0.39 \\
\hline Elevated blood pressure \% & 48.1 & 47.5 & $56.3^{*}$ & $<0.05$ \\
\hline Elevated fasting glucose $\%$ & 55.3 & 52.5 & 55.7 & 0.62 \\
\hline Smoking history $\%$ & & & & $<0.001$ \\
\hline Never smokers & 33.3 & 26.6 & 14.7 & \\
\hline Former smokers & 39.7 & 40.7 & 39.9 & \\
\hline Current smokers & 27.0 & $32.7^{*}$ & $45.4^{* \#}$ & \\
\hline Pack-years & $18.0 \pm 19.1$ & $25.3 \pm 21.8^{*}$ & $37.5 \pm 27.6^{* \#}$ & $<0.001$ \\
\hline Alcohol intake \% & & & & 0.22 \\
\hline Non-drinkers & 22.6 & 26.3 & 30.7 & \\
\hline $1 \sim 2$ days/week & 13.6 & 8.8 & 10.1 & \\
\hline $3 \sim 4$ days/week & 10.6 & 6.7 & 8.0 & \\
\hline $5 \sim 6$ days/week & 13.6 & 11.1 & 9.5 & \\
\hline Everyday drinkers & 39.6 & 47.1 & 41.7 & \\
\hline \multicolumn{5}{|c|}{$\begin{array}{l}\mathrm{FEV}_{1}=\text { Forced expiratory volume in one second, } \mathrm{FEV}_{1} / \mathrm{FVC}=\text { Forced expiratory volume in one second/Forced } \\
\text { vital capacity, Pack-years }=(\text { number of cigarettes smoked per day } \times \text { number of years smoked }) / 20 \text {, } \\
\mathrm{HDL}=\text { high-density lipoprotein. } \\
\text { Airflow obstruction was defined as } \mathrm{FEV}_{1} / \mathrm{FVC}<70 \% \text {. }\end{array}$} \\
\hline \multicolumn{5}{|c|}{$\begin{array}{l}\text { The severity of airflow obstruction was defined as follows: GOLD stage } \mathrm{I} \text { : } \mathrm{FEV}_{1} / \mathrm{FVC}<70 \% \text { and } \mathrm{FEV}_{1} \geq 80 \% \\
\text { predicted; GOLD stage II } \sim \mathrm{IV}: \mathrm{FEV}_{1} / \mathrm{FVC}<70 \% \text { and } \mathrm{FEV} \mathrm{V}_{1}<80 \% \text { predicted }\end{array}$} \\
\hline $\begin{array}{l}\text { Data were analyzed by analysis of } \\
\text { post-hoc Bonferroni adjustment. }\end{array}$ & ince and post-h & Tukey test or Man & hitney $U$ test and & \\
\hline
\end{tabular}

(SD) and categorical variables are expressed as frequencies. Analysis of variance (ANOVA) with a post hoc Turkey's test and the Mann-Whitney U test with post-hoc Bonferroni adjustment were used to assess the difference in characteristics by lung function status. Logistic regression model adjusted for age, BMI, smoking, and alcohol intake was used to assess the relationship between airflow obstruction and MS or its components. All analyses were done using IBM SPSS Statistics 18 software.

\section{Results}

The prevalence of airflow obstruction was $9.0 \%$ in this study, which was similar to that reported previously in a Japanese male population $(3,14)$. The prevalences of airflow obstruction in this study population for GOLD stages I-IV were: $4.1 \%(n=297), 4.4 \%(n=318), 0.4 \%(n=26)$, and $0.1 \%$ $(n=4)$, respectively. The characteristics of the subjects by lung function stage are presented in Table 1. Significant differences of lung function status were seen in relation to age, weight, body fat, BMI, $\mathrm{FEV}_{1} \%$ predicted, $\mathrm{FEV}_{1} / \mathrm{FVC}$, waist 
Table 2. Relationship between Airflow Obstruction and Metabolic Syndrome or Its Components According to Severity of Airflow Obstruction

\begin{tabular}{|c|c|c|c|}
\hline & \multirow{2}{*}{$\begin{array}{l}\text { Normal lung function } \\
\qquad(\mathrm{n}=6,544)\end{array}$} & \multicolumn{2}{|c|}{ Airflow obstruction } \\
\hline & & $\begin{array}{l}\text { GOLD stage I } \\
\quad(n=297)\end{array}$ & $\begin{array}{l}\text { GOLD stage II } \sim \mathrm{IV} \\
\quad(\mathrm{n}=348)\end{array}$ \\
\hline n (\%) with metabolic syndrome & $1,691(25.8)$ & $50(16.8)$ & $100(28.7)$ \\
\hline Crude OR $(95 \% \mathrm{Cl})$ & 1.00 & $0.58(0.43-0.79)$ & $1.16(0.91-1.47)$ \\
\hline Adjusted OR (95\%) & 1.00 & $0.72(0.51-1.02)$ & $1.33(1.01-1.76)$ \\
\hline $\mathrm{n}(\%)$ with elevated waist circumference & $1,884(28.8)$ & $53(17.8)$ & $104(29.9)$ \\
\hline Crude OR $(95 \% \mathrm{Cl})$ & 1.00 & $0.54(0.40-0.73)$ & $1.05(0.83-1.33)$ \\
\hline Adjusted OR (95\%) & 1.00 & $0.94(0.62-1.43)$ & $1.76(1.24-2.50)$ \\
\hline n (\%) with elevated triglycerides & $2,381(36.4)$ & $91(30.6)$ & $119(34.2)$ \\
\hline Crude OR $(95 \% \mathrm{Cl})$ & 1.00 & $0.77(0.60-0.99)$ & $0.91(0.72-1.14)$ \\
\hline Adjusted OR (95\%) & 1.00 & $0.91(0.70-1.18)$ & $0.91(0.72-1.16)$ \\
\hline n $(\%)$ with reduced HDL-cholesterol & $285(4.4)$ & $11(3.7)$ & $20(5.7)$ \\
\hline Crude OR $(95 \% \mathrm{Cl})$ & 1.00 & $0.85(0.46-1.56)$ & $1.34(0.84-2.14)$ \\
\hline Adjusted OR (95\%) & 1.00 & $1.00(0.53-1.89)$ & $1.20(0.74-1.97)$ \\
\hline n (\%) with elevated blood pressure & $3,148(48.1)$ & $141(47.5)$ & $196(56.3)$ \\
\hline Crude OR $(95 \% \mathrm{Cl})$ & 1.00 & $0.98(0.77-1.23)$ & $1.39(1.12-1.73)$ \\
\hline Adjusted OR (95\%) & 1.00 & $0.83(0.65-1.07)$ & $1.37(1.08-1.74)$ \\
\hline $\mathrm{n}(\%)$ with elevated fasting glucose & $3,621(55.3)$ & $156(52.5)$ & $194(55.7)$ \\
\hline Crude OR $(95 \% \mathrm{Cl})$ & 1.00 & $0.89(0.71-1.13)$ & $1.02(0.82-1.26)$ \\
\hline Adjusted OR (95\%) & 1.00 & $0.90(0.70-1.14)$ & $1.02(0.81-1.28)$ \\
\hline \multicolumn{4}{|l|}{ HDL = high-density lipoprotein. } \\
\hline \multicolumn{4}{|c|}{ Adjusted for age, BMI, smoking, and alcohol intake. } \\
\hline \multicolumn{4}{|c|}{ Airflow obstruction was defined as forced expiratory volume in one second $\left(\mathrm{FEV}_{1}\right) /$ forced vital capacity $(\mathrm{FVC})<70 \%$} \\
\hline The severity of airflow obstruction was de & follows: GOLD stage & $\mathrm{C}<70 \%$ and $\mathrm{FEV}_{1}$ & icted; \\
\hline GOLD stage II IV: $\mathrm{FEV}_{1} / \mathrm{FVC}<70 \%$ and & $80 \%$ predicted & & \\
\hline \multirow{2}{*}{\multicolumn{4}{|c|}{$\begin{array}{l}\text { Elevated waist circumference: waist circumference } \geq 90 \mathrm{~cm} \text {; elevated triglycerides: } \geq 150 \mathrm{mg} / \mathrm{dL} \\
\text { reduced HDL-cholesterol: }<40 \mathrm{mg} / \mathrm{dL} \text {, or treatment for dyslipidaemia; elevated blood pressure }\end{array}$}} \\
\hline & & & \\
\hline \multicolumn{4}{|c|}{$\geq 130 / 85 \mathrm{mmHg}$, or antihypertensive drug treatment in a patient with a history of hypertension; elevated fasting glucose; } \\
\hline
\end{tabular}

circumference, triglycerides, systolic blood pressure, diastolic blood pressure, pack-years, and frequency of smoking. The frequencies of MS in subjects with normal lung function, GOLD stages I, and stages II-IV, were $25.8 \%, 16.8 \%$ and $28.7 \%$, respectively (average, $25.6 \%$ ). The frequencies of MS in this study was similar to that reported previously in a Japanese male population $(25.3 \%)(22)$. Significant differences of lung function status were seen in the frequency of MS, elevated waist circumference, elevated blood pressure, and treatment for dyslipidemia and hypertension.

Table 2 shows the relationship between airflow obstruction and MS or its components according to severity of airflow obstruction. In logistic regression models adjusting for age, BMI, smoking, and alcohol, the risk of MS was higher in subjects in GOLD stage II-IV compared to those with normal lung function [odds radio (OR), 1.33; 95\% confidence interval $(95 \% \mathrm{CI}), 1.01-1.76)]$. Of the five components of MS, waist circumference (OR, 1.76; 95\% CI, 1.24$2.50)$ and blood pressure (OR, 1.37; 95\% CI, 1.08-1.74) were significantly associated with airflow obstruction of GOLD stage II-IV, after controlling for potential confounders (Table 2).

Figure 1 shows markers of inflammation and lung function status. CRP was significantly higher in the subjects in GOLD stage II-IV than in those with normal lung function. White blood cell count was significantly higher in the sub- jects with GOLD stage II-IV than in those with normal lung function or GOLD stage I (Fig. 1).

\section{Discussion}

In the present study, we found that subjects with airflow obstruction of GOLD stage II-IV had a significantly higher prevalence of MS than those with normal lung function. In addition, we found that of the five components of MS, waist circumference and blood pressure were significantly associated with airflow obstruction of GOLD stage II-IV according to logistic regression models adjusting for age, BMI, smoking, and alcohol. Our results appear to agree with two previous studies, which suggested that airflow obstruction was associated with MS $(12,13)$. Marquis et al however, in their case-control study of 38 Canadian patients with COPD (23 males, 15 females), found that $60.9 \%$ of male patients and $26.7 \%$ female patients with COPD had MS as defined by NCEP ATP III criteria (12). Furthermore, Lam et al (13) investigated whether airflow obstruction, in tests done without the use of bronchodilators, was associated with MS as defined by the International Diabetes Federation (IDF) criteria in 7,358 adults (2,008 men and 5,350 women) aged 50 years and older, from Guangzhou, China. Lam et al found that, though the likelihood for MS increased with increasing severity of airflow obstruction, this relationship was not sig- 

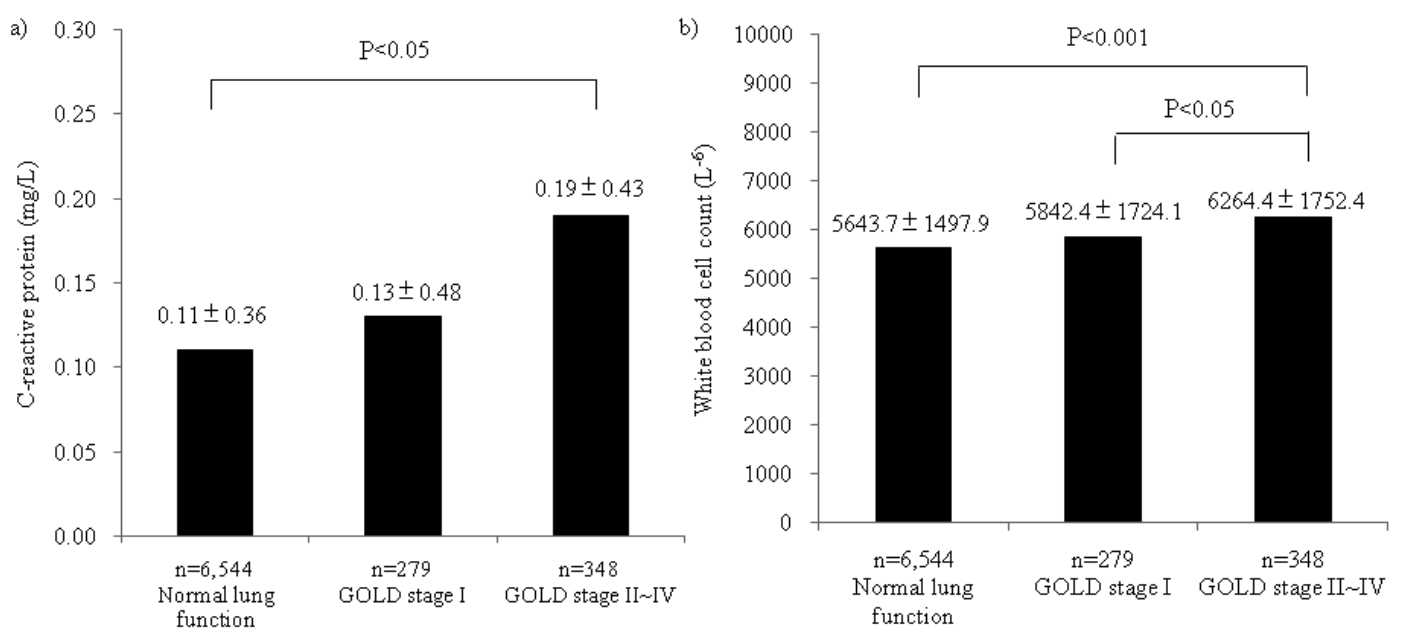

Figure 1. Markers of inflammation and lung function status. a) C-reactive protein levels and lung function status. b) White blood cell count levels and lung function status.

nificant in subjects with airflow obstruction of GOLD stage I or II. We also did not observe a significant association between GOLD stage I airflow obstruction and MS in this study. It is thus possible that advanced airflow obstruction might be associated with MS.

In the present study, we found that among the components of MS, abdominal obesity (waist circumference) and blood pressure were the main effects linked with airflow obstruction. Consistent with our study results, Marquis et al reported that among MS components, abdominal obesity and high blood pressure were more frequent in COPD men (12). High blood pressure was especially frequent in COPD men (82\%) (12). Recent analysis of data from 20,296 subjects (11,258 men and 9,038 women) aged $\geqq 45$ years in two large combined cohort studies showed that subjects with GOLD stage II-IV had a higher prevalence of hypertension (23).

In contrast with our results, Lam et al detected no association between airflow obstruction and hypertension, and found that among the five components of MS, only central obesity was significantly associated with airflow obstruction (13). In addition, with regard to severity of airflow obstruction, a significant relationship was only observed in subjects with airflow obstruction of GOLD stage II or higher after controlling for potential confounders. Another cross-sectional study in France also revealed that abdominal obesity was positively related to both obstructive and restrictive lung function impairment (24). For mechanical effects of obesity on lung function, respiratory muscle weakness in obesity has been attributed to muscle inefficiency, a result of reduced chest wall compliance or lower operating lung volumes or both (25). As an alternative hypothesis to a mechanical problem, Lam et al suggested that the inflammatory response in MS is particularly related to central obesity, as demonstrated by elevated levels of CRP in those with higher waist circumference (13), however, they did not study the relationship between levels of CRP and airflow obstruction. Waist circumference is correlated with both subcutaneous adipose tissue and intraabdominal adipose tissue. Intraabdominal adipose tissue is an active endocrine organ, which correlates positively with circulating levels of the proinflmmatory adipocytokines, IL-6, tumor necrosis factoralpha (TNF-alpha), and leptin, and negatively with levels of adiponectin, which regulates insulin sensitivity and could exert anti-inflammatory activities (26). The role of adipose tissue in the pathogenesis of chronic respiratory diseases remains poorly understood, but adipose tissue may act as an additional source of systemic inflammation $(24,27)$.

In this study, subjects with airflow obstruction (GOLD stage I or II-IV) had greater smoking exposure and packyears than those with normal lung function. In addition, subjects with airflow obstruction of GOLD stage II-IV showed a significantly higher CRP and white blood cell count than those with normal lung function (Fig. 1). Gan et al reported a systematic review and meta-analysis of 14 reports which confirmed the strong association between COPD and biological markers of systemic inflammation such as CRP, fibrinogen, white blood cell count and tumor necrosis factoralpha (TNF-alpha) (8). Among the markers of systemic inflammation, CRP has been most widely studied. CRP levels seem to relate to outcomes in COPD. In a cohort of 1,302 subjects with airflow obstruction, selected from the Copenhagen City Heart Study, subjects with baseline CRP greater than $3 \mathrm{mg} / \mathrm{L}$ had a higher risk of death from COPD, compared with subjects with a baseline CRP less than or equal to $3 \mathrm{mg} / \mathrm{L}$ adjusted for age, sex, $\mathrm{FEV}_{1} \%$ predicted, smoking, and ischemic heart disease during 8 years of follow-up (28). In addition, a previous study of data from 65 subjects (10 non smokers, 11 healthy smokers, 17 stage 0 COPD, 10 stage I COPD, 17 stage II-IV COPD) showed that relative neutrophil counts were significantly higher in stage II-IV COPD than in all other groups (29). Ishizaka et al found that in the cross-sectional data from 3687 Japanese men, an elevated white blood cell count is a risk factor for MS defined by the Japanese criteria (30). Cassatella described that in addition to the traditional functions such as phagocytosis, 
degranulation and production of superoxide, neutrophils can express a variety of inflammatory mediators (31). It remains unclear whether systemic inflammation is a cause of COPD or merely a marker, but systemic inflammatory markers may have important pathophysiological and therapeutic implications in subjects with COPD (10). Attenuation of systemic inflammation may offer new perspectives in the management of COPD patients in order to reduce the burden of exacerbations. On the other hand, consistent with a previous study (13), we did not find any association among airflow obstruction of GOLD stage I, MS or its components, CRP and white blood cell count. A concern has been raised that GOLD stage I is not necessarily a COPD risk factor (32). Further studies are needed to answer the question on this point.

The current study had some limitations. First, the present study did not employ reversibility testing, as it was unacceptable to the authors' Institutional Review Board with there being no high suspicion of disease. $\mathrm{FEV}_{1}$ and other respiratory indices obtained without bronchodilation are good markers of overall health (33). The degree of reversibility of airflow limitation is no longer recommended for diagnosis, differential diagnosis with asthma (1). A modified GOLD definition omitting bronchodilation has been widely adopted by population based epidemiological studies (2).

Second, we assessed only men, because there were too few females with airflow obstruction. Relative to men, advanced COPD in women is characterized anatomically by smaller airway lumens and disproportionately thick airway walls, and emphysema that is less extensive, manifest by a smaller hole size and less peripheral involvement (34). Further studies about the sex differences in association between airflow obstruction and MS are required in Japanese females.

In conclusion, our results suggest that airflow obstruction of GOLD stage II-IV was associated with MS, and in particular, waist circumference and blood pressure components in Japanese men.

\section{Acknowledgement}

The authors would like to thank Yoko Wakaki and Hiroyuki Higashi for their excellent technical assistance.

\section{Conflict of Interest}

None of the authors have a conflict of interest to declare in relation to this work.

\section{References}

1. Global Initiative for Chronic Obstructive Lung Disease, April, 2001. Update 2009: Global Strategy for the diagnosis, management, and prevention of chronic obstructive pulmonary disease, NHLBI/WHO Workshop Report. Bethesda, National Heart, Lung and Blood Institute. http://www.goldcopd.com.Accessed:19 April 2010.

2. Murray CJ, Lopez AD. Alternative projections of mortality and disability by cause 1990-2020: Global Burden of Disease Study. Lancet 349: 1498-1540, 1997.
3. Fukuchi Y, Nishimura M, Ichinose M, et al. COPD in Japan: the Nippon COPD Epidemiology study. Respirology 9: 458-465, 2004.

4. Chatila WM, Thomashow BM, Minai OA, Criner GJ, Make BJ. Comorbidities in chronic obstructive pulmonary disease. Proc Am Thorac Soc 5: 549-555, 2008.

5. Fabbri LM, Luppi F, Beghé B, Rabe KF. Complex chronic comorbidities of COPD. Eur Respir J 31: 204-212, 2008.

6. LM Fabbri, KF Rabe. From COPD to chronic systemic inflammatory syndrome? Lancet 370: 797-799, 2007.

7. Sin DD, Man SF. Systemic inflammation and mortality in chronic obstructive pulmonary disease. Can Physiol Pharmacol 85: 141147, 2007.

8. Gan WQ, Man SF, Senthilselvan A, Sin DD. Association between chronic obstructive pulmonary disease and systemic inflammation: a systematic review and meta-analysis. Thorax 59: 574-580, 2004.

9. Margretardottir OB, Thorleifsson SJ, Gudmundsson G, et al. Hypertension, systemic inflammation and body weight in relation to lung function impairment-an epidemiological study. COPD 6: 250-255, 2009.

10. Spurzem JR, Rennard Sl. Pathogenesis of COPD. Semin Respir Crit Care Med 26: 142-153, 2005.

11. Dandona P, Aljada A, Chaudhuri A, Mohanty P, Garg R. Metabolic syndrome: a comprehensive based on interactions between obesity, diabetes, and inflammation. Circulation 111: 1448-1454, 2005.

12. Marquis K, Maltais F, Duguay V, et al. The metabolic syndrome in patients with chronic obstructive pulmonary disease. J Cardiopulm Rehabil 25: 226-232, 2005.

13. Lam KB, Jordan RE, Jiang CQ, et al. Airflow obstruction and the metabolic syndrome: the Guangzhou Biobank Cohort Study. Eur Respir J 35: 317-323, 2010.

14. Omori H, Nonami Y, Mihara S, Marubayashi T, Morimoto Y, Aizawa $\mathrm{H}$. Prevalence of airflow limitation on medical check-up in Japanese subjects. JUOEH 29: 209-219, 2007.

15. Grundy SM, Cleeman JI, Daniels SR, et al. American Heart Association; National Heart, Lung, and Blood Institute. Diagnosis and management of the metabolic syndrome: an American Heart Association/National Heart, Lung, and Blood Institute Scientific Statement. Circulation 112: 2735-2752, 2005.

16. Omori H, Nakashima R, Otsuka N, et al. Emphysema detected by lung cancer screening with low-dose spiral CT: prevalence, and correlation with smoking habits and pulmonary function in Japanese male subjects. Respirology 11: 205-210, 2006.

17. Japanese Society of Chest Disease. Standards of pulmonary function tests for Japanese. J Thorac Dis 31: appendix, 1993.

18. Mannino DM, Buist AS, Petty TL, Enright PL, Redd SC. Lung function and mortality in the United States: data from the First National Health and Nutrition Examination Survey follow up study. Thorax 58: 388-393, 2003.

19. Stavem K, Sandvik L, Erikssen J. Can global initiative for Chronic Obstructive Lung Disease stage 0 provide prognostic information on long-term mortality in men? Chest 130: 318-325, 2006.

20. Ekberg-Aronsson M, Pehrsson K, Nilsson JA, Nilsson PM, Löfdahl CG. Mortality in GOLD stages of COPD and its dependence on symptoms of chronic bronchitis. Respir Res 6: 98, 2005.

21. Carrasco Garrido P, de Miguel Díez J, Rejas Gutiérrez J, et al. Negative impact of chronic obstructive pulmonary disease on the health-related quality of life of patients. Results of the EPIDEPOC study. Health Qual Life Outcomes 4: 31, 2006.

22. Takeuchi H, Saitoh S, Takagi S, et al. Metabolic syndrome and cardiac disease in Japanese men: applicability of the concept of metabolic syndrome defined by the National Cholesterol Education Program-Adult Treatment Panel III to Japanese men-the Tanno and Sobetsu Study. Hypertens Res 28: 203-208, 2005. 
23. Mannino DM, Thorn D, Swensen A, Holguin F. Prevalence and outcomes of diabetes, hypertension and cardiovascular disease in COPD. Eur Respir J 32: 962-969, 2008.

24. Leone N, Courbon D, Thomas F, et al. Lung function impairment and metabolic syndrome: the critical role of abdominal obesity. Am J Respir Crit Care Med 179: 509-516, 2009.

25. Poulain M, Doucet M, Major GC, et al. The effect of obesity on chronic respiratory disease: pathophysiology and therapeutic strategies. CMAJ 179: 1293-1299, 2006.

26. Fantuzzi G. Adipose tissue, adipokines, and inflammation. J Allergy Clin Immunol 115: 911-919, 2005.

27. Franssen FM, O'Donnell DE, Goossens GH, Blaak EE, Schols AM. Obesity and the lung: 5. Obesity and COPD. Thorax 63: 1110-1117, 2008.

28. Dahl M, Vestbo J, Lange $P$, et al. C-reactive protein as a predictor of prognosis in chronic obstructive pulmonary disease. Am J Respir Crit Care Med 175: 250-255, 2007.

29. O'Donnell RA, Peebles C, Ward JA, et al. Relationship between peripheral airway dysfunction, airway obstruction, and neutrophilic inflammation in COPD. Thorax 59: 837-842, 2004.

30. Ishizaka N, Ishizaka Y, Toda E, Nagai R, Yamakado M. Association between cigarette smoking, white blood cell count, and metabolic syndrome as defined by the Japanese criteria. Intern Med 46: 1167-1170, 2007.

31. Cassatella MA. Neutrophil-derived proteins: selling cytokines by the pound. Adv Immunol 73: 369-509, 1999.

32. Enright PL. GOLD stage $I$ is not a COPD risk factor. Thorax 62 : 1107, 2007.

33. Soriano JB, Zielinski J, Price D. Screening for and early detection of chronic obstructive pulmonary disease. Lancet 374: 721-732, 2009.

34. Viegi G, Scognamiglio A, Baldacci S, Pistelli F, Carrozzi L. Epidemiology of chronic obstructive pulmonary disease (COPD). Respiration 68: 4-19, 2001.

(C) 2010 The Japanese Society of Internal Medicine http://www.naika.or.jp/imindex.html 